\title{
The relative contribution of some physiological variables of the heart muscle and the left and right ventricles for junior swimmers"
}

\author{
Magdy Mohammed Abu Zaid ${ }^{(*)}$ \\ Mahmoud Medhat Arif ${ }^{(* *)}$ \\ Ziad Mohammed Amin ${ }^{(* *)}$ \\ Mustafa Mahmoud Dowidar ${ }^{(* * *)}$
}

\section{Introduction:}

Modern scientific studies and research which is carried out to measure and evaluate athletes physiological fitness are of great concern among sports medicine and physical education and sport scientists, in particular study and evaluation of heart and respiratory system efficiency, these studies are interested in identifying the response resulting from implementing training programs and methods and its effect and how it achieved the goal which it was set for, which ensures identify chronic physiological responses resulting from implementing training programs which lead to different development of body systems biological functions. Sports training puts additional burdens on body organs where these organs begin to adapt to these burdens, heart muscle is of most important of these members as it adapts to these burdens by physiological changes resulting from it an increase in the functional efficiency of athlete's heart, the cardiovascular system is considered one of the important vital organs that directly respond to athletic training, and response varies depending on type of activity and individual's efficiency level.

Abdel Fattah (1997, 23-25) argues that athlete's heart is the heart which is physiology with adaptive with training or it is good health heart with high efficiency functions, especially when exercising kinetic models sports characterized by high intensity.

Ali (1994) indicated that athlete's heart is of great significance in transferring oxygen to tissues and also rid it of carbon dioxide, so lack of sufficient growth of heart function can have a negative effect on physical efficiency, especially in sports activities that require increased efficiency of the respiratory circulatory system (18: 110-112(

Abu Zaid (2013) mentions that the body's horizontal position in swimming is of core influences in improving heart functions, where heart work smoothly, efficiently and regularly in blood distribution balance; so blood evenly distributed between body parts, aqueous medium is considered a contributing factor in reducing body weight, the matter which reduces the burden on heart muscle compared vertical position in standing.

Al-Bek $(2009,25-26)$ argues that sports training aims at getting the individual to the highest athletic levels in practiced activity through use of physical load and through high physiological, psychological and mental requirements which develop individual's abilities and skills, it also aims at maintaining individual 's overall health and fitness. This object can be achieved in training process only through a set of duties.

Helmi (1998, 17-18) recommended that young endurance training have to be with high volumes and intensities as adults, taking into account physical and physiological abilities.

\footnotetext{
${ }^{*}$ Swimming Professor, water sports training department, Faculty of Physical Education for Men, Alexandria university

${ }^{(* *)}$ Lecturer, water sports training department, Faculty of Physical Education for Men, Alexandria university

${ }^{(* * *)}$ Swimming Lecturer, and swimming technical director, Kazma Club, Kuwait
} 
Abu Zaid (2013) mention that training plan for beginners is of the important topics to ensure training process success and achievement of sport creativity and future records, which should be achieved by junior, and this include setting short rum, direct and long run objectives that achieve access to high levels

Abu Zaid (2013) adds that training program planning is responsible for junior swimmer's future which gets him to be a champion; this program should be characterized with inclusiveness and balance between training volume and its effect on heart muscle and respiratory system.

Darwish and Abdul Salam $(2007,145)$ explained that athletic heart forming process are gradually done over several years of training, depending on age, sport type, training load level. Age is of the main factors that determine individual possibility to have athletic heart as it easier to make changes in heart muscle during its growth and development, while this opportunity is not lowered if heart muscle growth was completed

Abu Zaid (2008) argues that studying junior athletes biological characteristics aims to identify the extent swimming training programs effect on the biological changes, specially on the heart muscle and respiratory system and identify athletic child 's ability and his vital system adaptation to performance of intense physical training. Biological characteristics are of the important growth characteristics and follow it up according to age, it is also possible to utilize it in setting children's physical growth dynamic for athletic children.

Ali (2000) reports that lack of sufficient growth heart size and function can have a negative effect on physical efficiency, especially for some sports that require an increase in circulatory system efficiency.

Abdul Hadi (2001, 283) mention that heart is the muscle pump, and consists of four separate cavities and four valves, it assume continued blood circulation moving to all body parts.

Powers and Howely (1994) indicates that heart has four chambers, it is two pumps together; right atrium and right ventricle make the right pump, left atrium and left ventricle make the left pump, A thick wall called the septum separates the left side of the heart from the right to prevent blood contamination between the two parts of the heart. Blood goes in one direction form atrium to ventricle and from ventricle to arteries. Four valves prevent prevent backflow, they are The two Atrioventricular (AV) valves, the mitral valve (bicuspid valve), and the tricuspid valve, which are between the upper atria and the lower ventricles, and The two semilunar (SL) valves, the aortic valve and the pulmonary valve, which are in the arteries leaving the heart. The mitral valve and the aortic valve are in the left heart; the tricuspid valve and the pulmonary valve are in the right heart. The complete heartbeat from its generation to the beginning of the next beat is called t consists of Diastole which is the part of the when the heart refills with blood following and systole which is the period of ventricular contraction where blood is pumped from heat to body parts through aorta artery.

Zaher $(2005,117)$ explains that Echocardiography is of modern scientific equipment, which allowed knowing a lot about heart structure functions in terms chambers dimensions, its cave and wall size and thickness, its main valves and arteries, and blood circulation and speed inside it

Weyman. (1994, 4-10) explains that ultrasound science used is used to diagnose heart cases and called Echocardiography or drawing an echo using ultrasound, and this based on the rule that sound spread making disturbance in pressure through the medium, and that sound wave is a series of pressures and dislocations made up of one session, where the idea of using ultrasound is to issue an ultrasonic pulse going in the form of positive rays till it collides with 
the body to be studied, it reflect an echo (arising out of beam collision with body) and there are electrical signal receives this echo and transform it into visible diagrams on the screen of the device

Fuster, Alexander, O'rourke, Roberts, King.\& Wellens (2006) indicate that heart pumps about 4.5 - 5 liters of blood per minute and this is doubled during athletic activity.

Zaher (2011) argues that heart muscle swells as is the case of skeletal muscles in response to the workload, it is naturally adaption of the heart muscle as a result of intensive physical training for a period of time, which make it more efficient in carrying out the requirements of the physical effort and the change in heart size and its wall thickness fepend on physical training.

Abu Zaid (2013) in his study which was designed to identify the dynamic development of heart functions associated with regularity in swimming training for 12 years swimmers, improvement percentage order in heart muscle associated with regularity in swimming training for 12 years swimmers, identify the occurring extent of athletic heart phenomenon in swimmers in pre-adulthood swimmers as a result of regular swimming training programs during the training season, identify record level achieved for $50 \mathrm{~m}, 100 \mathrm{~m}$ freestyle swimming after the training program for swimmers children (research sample), The results confirmed the effect of swimming training on the athletic heart formation for swimmers children (research sample), Heart function, size and thickness The dimensions of the left ventricle improved to nearly sizes, dimensions thickness of heart muscle for athletes aged more than twenty years. The matter which demonstrates a significant effect of swimming training on 12 years swimmers in improving heart functions and structure

Dahab, Ali, and Abdel Nasser (2008) in their study which was aimed at identifying heart morphological and functional changes and some blood hormones changes within swimmers in aged 11-16 years indicated that results revealed that regular swimming exercise lead to positive changes in heart morphological and functional characteristics and that characteristics grow naturally with age, and training. there was an increase in testosterone and thyrotropin in the blood of swimmers. Researchers recommended to use heart morphological and functional characteristics as swimmers selection indicator and stressed on measure morphological and functional periodically to be used as an indicator to judge physiological adaptation to training loads and thus development of training programs.

Pelliccia et al (2014) in their study results revealed increase in atria size after sports training within female athletes.

Ayabakan, and Akalin. (2006) results explained that heart examining after training by ultrasound there was increase in the left ventricle wall thickness

Krol W, and Braksator (2011) study results revealed that there was no significant differences in right ventricles between athletes and healthy people practice sports activity

, Koc (2007) results reveal that left and right measurements were higher within athletes compared to others with exception of blood circulation rate, Diastolic speed increased for both ventricle, and even ventricles size increased but the ratio between them was constant

Through the vital role of modern scientific research and studies conducted to evaluate the cardiac and respiratory system efficiency, it is clear that higher achievement is linked standardized training programs, which are performed on a regular basis, occurs from it quick and regular developments in functional, physical and skill efficiency and contribution of these variables for achieved records for those events including swimming, which is of the events that required special physical preparation in order to raise player's physical and physiological 
efficiency, as the physiological variables is a reflection of physical effort, which in turn affects the raising these abilities, within these are swimming events (improved achievement for record for 50-meter, 100-meter and .200-meter freestyle swimming). This demonstrates the importance of heart left and right ventricles morphological variable contribution in time of 100-meter and .200-meter freestyle swimming, hence current research importance is clear and is represented in defining the contribution of these variables with training efforts to identify the effect of training programs on these morphological variable and swimmers achievement record development.

\section{Research objective:}

- Identify contribution percentage of some physiological variables (dimensions and thickness) of heart muscle left and right ventricles in junior swimmers $50 \mathrm{~m}, 100 \mathrm{~m}$, $200 \mathrm{~m}$ freestyle swimming time

- Predict record level for $50 \mathrm{~m}, 100 \mathrm{~m}$, and 200 meter freestyle junior swimmers knowing some physiological variables (dimensions and thickness) of heart muscle

\section{Research queries:}

1- What are the physiological variables (size and thickness) of heart left and right ventricles most contribute in 50-meter freestyle swimming time?

2- What are the physiological variables (size and thickness) of heart left and right ventricles most contribute in 1000-meter freestyle swimming time?

3- What are the physiological variables (size and thickness) of heart left and right ventricles most contribute in 200-meter freestyle swimming time?

4- Is it possible to predict achievement record using physiological variables (size and thickness) of heart left and right ventricles

\section{Research procedures:}

Research methodology: descriptive approach was used due to its suitability for this study

Research sample: The study was conducted on (30) swimmers aged 12 years with 3 years swimming training from Kazma club who participated in Arab and international swimming competitions.

Time field: 2015 training season.

Spatial domain: pre measurements, training program, and post measurements were conducted at Kazma club and Sabah hospital in Kuwait with assistant of and the application of the training program and a posteriori measurements in Kazma Club and hospital the morning of the heart in Kuwait.

All measurements was done with assistance from a cardiologist ( $\mathrm{PhD}$ in heart disease and blood vessels and cardiologist consultant)

\section{Devices used:}

- Echocardiograph (General Electric. Vivid E9) to assess heart morphological statues

- Identify body surface area Surface using Dubois chart to of relationship between height $(\mathrm{cm})$ and weight $(\mathrm{kg})$

- Stethoscope to measure heart rate

- Medical thermometer to measure body weight,

- Restameter to measure height 
- Digital stop watch

\section{Data collection tools}

Researchers selected a group of tests, which are;-

\section{Measurements to assess heart muscle through Echocardiography device:}

Used under supervision of cardiologist to find the following measurements

- Basic measurements: Height, weight and age

- Skill measurements: Measuring 50 meter, 100m and 200m freestyle swimming time

- Cardiovascular measurements (Physiological variables for left and right ventricles : Right ventricle end - diastolic dimension ( RVEDD ), Right ventricle end Systolic dimension (RVESD ), Left ventricle end Systolic dimension (LVESD ), Left ventricle end - diastolic dimension ( LVEDD), Posterior wall thickness in diastole (PWTD ), Posterior wall thickness in systole ( PWTS ), Inter ventricular septum thickness in diastole ( IVSTD ), Inter ventricular septum thickness in systole (IVSTS), Left Ventricle Mass ( LV Mass ).

Measurements conducted during the training season in 2015 under supervision of cardiologist

1- Right ventricle end - diastolic dimension ( RVEDD), Measured by vertical distance from the echo of the inner layer of rear wall of the right ventricle to echo the right side inner layer of the septum and measured at the top of $\mathrm{R}$ wave of ECG

2- Right ventricle end Systolic dimension (RVESD )

Measured by vertical distance from the echo of the inner layer of rear wall of the right ventricle to echo the right side inner layer at lower point of septum movement

3- Left ventricle end Systolic dimension (LVESD)

Measured by vertical distance from the echo of the inner layer of rear wall of the left ventricle to echo the left side inner layer of the septum and measured at the top of $\mathrm{R}$ wave of ECG

4- Left ventricle end - diastolic dimension ( LVEDD)

Measured by vertical distance from the echo of the inner layer of rear wall of the left ventricle to echo the right side inner layer at lower point of septum movement

5- Posterior wall thickness in diastole ( PWTD )

Measured by vertical distance between inner and outer layers for rare wall at top of $\mathrm{R}$ wave of ECG

6- Posterior wall thickness in systole ( PWTS )

Measured by vertical distance between outer layers to the outmost point on surface of inner layer of rare wall (rare wall is about $9-12 \mathrm{~cm}$ far from Transducer which is perpendicular on chest in $3^{\text {rd }}, 4^{\text {th }}, 5^{\text {th }}$ spaces between RIBS)

7- Inter ventricular septum thickness in diastole (IVSTD )

Measured by vertical distance between right side to left side surface of inner layer of Inter ventricular septum at top of R wave of ECG

8- Inter ventricular septum thickness in systole (IVSTS) 
Measured by vertical distance between right side to outmost point on left side surface of Inter ventricular septum

9- Left Ventricle Mass ( LV Mass ).

LV mass $=1.04\left[(\text { PWTD }+ \text { IVSD }+ \text { LVEDD })^{3}-(\text { LVEDD })^{3}\right]-13.6$

\section{The training program}

- The training program consisted of (16) training weeks distributed as follows:

- General preparation period: 4 weeks with water training volume equal to $147 \mathrm{~km}$

- Special preparation period: 6 weeks with water training volume equal to $134 \mathrm{~km}$

- Competition period: 2 weeks with water training volume equal to $50 \mathrm{~km}$

- Cool-down period: 1 week with water training volume equal to $15 \mathrm{~km}$

- Each week has 6 training sessions

- Total training session in the program equal to 96 training session

- Average training volume in the unit $=3.5 \mathrm{~km}$

- Total program training volume (16 weeks) $=340 \mathrm{~km}$

\section{Results and discussion:}

Table (1) Main sample statistical description in basic variables $(\mathrm{n}=30)$

\begin{tabular}{l|l|l|l|l|l}
\hline \hline \multicolumn{1}{c|}{ Statistics } & Mean & median & $\begin{array}{c}\text { standard } \\
\text { deviation }\end{array}$ & Kurtosis & $\begin{array}{c}\text { Skewness } \\
\text { coefficient }\end{array}$ \\
\hline \hline Age $($ year) & 11.267 & 11.5 & 0.634 & -1.307 & -0.283 \\
\hline Height $(\mathrm{cm})$ & 142.400 & 142 & 4.222 & -1.165 & 0.249 \\
\hline Weight $(\mathrm{kg})$ & 39.400 & 40 & 5.096 & -1.168 & -0.052 \\
\hline \hline
\end{tabular}

Table (1) results revel that skewness coefficient ranged between $(-0.283$ to 0.249$)$ which is values less than \pm 3 and very near to zero. Kurtosis coefficient (-1.168 to -1.307$)$ the matter indicates sample homogeneity in these variables.

Table (2) Main sample statistical description in morphological variables of $(n=30)$

\begin{tabular}{|c|c|c|c|c|c|c|}
\hline Variables & statistics & Mean & Median & $\begin{array}{l}\text { Standard } \\
\text { deviation }\end{array}$ & Kurtosis & $\begin{array}{r}\text { Skewness } \\
\text { coefficient }\end{array}$ \\
\hline \multirow[t]{4}{*}{$\begin{array}{l}\text { Ventricle } \\
\text { size }\end{array}$} & $\begin{array}{l}\text { Right ventricle end - diastolic dimension ( } \\
\text { RVEDD ) (cm) }\end{array}$ & 2.743 & 2.8 & 0.216 & 0.159 & -0.804 \\
\hline & $\begin{array}{l}\text { Right ventricle end Systolic dimension } \\
(\text { RVESD })(\mathrm{cm})\end{array}$ & 1.490 & 1.5 & 0.254 & -1.009 & 0.269 \\
\hline & $\begin{array}{l}\text { Left ventricle end - diastolic dimension ( } \\
\text { LVEDD) }(\mathrm{cm})\end{array}$ & 4.147 & 4.1 & 0.253 & 3.782 & 1.830 \\
\hline & $\begin{array}{l}\text { Left ventricle end Systolic dimension } \\
(\text { LVESD) }(\mathrm{cm})\end{array}$ & 2.773 & 2.9 & 0.221 & -0.692 & -0.867 \\
\hline \multirow[t]{4}{*}{$\begin{array}{l}\text { Ventricle } \\
\text { wall size }\end{array}$} & $\begin{array}{l}\text { Right Posterior wall thickness in diastole ( } \\
\text { RPWTD ) }(\mathrm{cm})\end{array}$ & 0.603 & 0.6 & 0.100 & 1.300 & 1.040 \\
\hline & $\begin{array}{l}\text { Left Posterior wall thickness in diastole ( } \\
\text { LPWTD })(\mathrm{cm})\end{array}$ & 0.757 & 0.8 & 0.101 & -0.991 & -0.086 \\
\hline & $\begin{array}{l}\text { Right Posterior wall thickness in systole ( } \\
\text { RPWTS) }(\mathrm{cm})\end{array}$ & 0.803 & 0.8 & 0.089 & -0.915 & -0.383 \\
\hline & $\begin{array}{l}\text { Left Posterior wall thickness in systole ( } \\
\text { LPWTS })(\mathrm{cm})\end{array}$ & 0.993 & 1.0 & 0.098 & -0.314 & 0.376 \\
\hline \multirow{3}{*}{$\begin{array}{l}\text { Inter ventricular } \\
\text { septum thickness } \\
\text { and Left ventricle } \\
\text { Mass }\end{array}$} & $\begin{array}{l}\text { Inter ventricular septum thickness in } \\
\text { diastole (IVSTD) }(\mathrm{cm})\end{array}$ & 0.857 & 0.9 & 0.119 & -0.388 & -0.624 \\
\hline & $\begin{array}{l}\text { Inter ventricular septum thickness in } \\
\text { systole (IVSTS) }(\mathrm{cm})\end{array}$ & 1.183 & 1.2 & 0.095 & -0.623 & -0.421 \\
\hline & Left Ventricular Mass ( LV Mass ) (gram) & 81.333 & 80.0 & 7.150 & -1.211 & 0.163 \\
\hline
\end{tabular}


Table (2) results revel that skewness coefficient ranged between (-0.867 to 1.830) which is values less than \pm 3 and very near to zero. Kurtosis coefficient (-1.211 to 3.782) the matter indicates sample homogeneity in these variables.

Table (3) Main sample statistical description in skill variables $(\mathrm{n}=30)$

\begin{tabular}{l|l|l|l|l|l}
\hline Statistics & \multicolumn{1}{|c|}{ Mean } & \multicolumn{1}{|c|}{ median } & $\begin{array}{c}\text { standard } \\
\text { deviation }\end{array}$ & \multicolumn{1}{|c|}{ Kurtosis } & $\begin{array}{c}\text { Skewness } \\
\text { coefficient }\end{array}$ \\
\hline $\begin{array}{l}\text { Initial variables M freestyle swimming } \\
\text { time (second) }\end{array}$ & 31.791 & 31.5 & 1.368 & -0.203 & 0.829 \\
\hline $\begin{array}{l}100 \quad \mathrm{M} \text { freestyle } \\
\text { swimming time (minutes) }\end{array}$ & 70.079 & 70.3 & 2.261 & 0.060 & -0.406 \\
\hline $\begin{array}{l}200 \quad \mathrm{M} \text { freestyle } \\
\text { swimming time (minutes) }\end{array}$ & 147.557 & 148.2 & 3.565 & 0.198 & -0.651 \\
\hline \hline
\end{tabular}

Table (3) results revel that skewness coefficient ranged between (-0.651 to 0.829) which is values less than \pm 3 and very near to zero. Kurtosis coefficient (- 0.203 to 0.198$)$ the matter indicates sample homogeneity in these variables.

Table (4) correlation coefficients between ventricles morphological variables and freestyle swimming time

\begin{tabular}{|c|c|c|c|c|}
\hline \multirow{2}{*}{ Variables } & \multirow[t]{2}{*}{ statistics } & \multicolumn{3}{|c|}{ Correlation coefficient with } \\
\hline & & \multirow{2}{*}{$\begin{array}{c}\mathbf{5 0} \mathbf{~ m} \\
\text { Freestyle } \\
\text { Swimming } \\
\text { time } \\
-0.304\end{array}$} & \multirow{2}{*}{$\begin{array}{c}100 \mathbf{~ m} \\
\text { freestyle } \\
\text { swimming } \\
\text { time } \\
-0.184\end{array}$} & \multirow{2}{*}{$\begin{array}{c}2000 \mathrm{~m} \\
\text { freestyle } \\
\text { swimming } \\
\text { time } \\
-0.134\end{array}$} \\
\hline $\begin{array}{l}\text { Ventricle } \\
\text { size }\end{array}$ & $\begin{array}{l}\begin{array}{l}\text { Right ventricle end - diastolic dimension ( RVEDD ) } \\
(\mathrm{cm})\end{array} \\
\end{array}$ & & & \\
\hline & Right ventricle end Systolic dimension (RVESD ) (cm) & $-0.441 *$ & $-0.437 *$ & $-0.425 *$ \\
\hline & Left ventricle end - diastolic dimension ( LVEDD) $(\mathrm{cm})$ & -0.273 & -0.247 & -0.194 \\
\hline & Left ventricle end Systolic dimension (LVESD) $(\mathrm{cm})$ & .073 & .303 & 217 \\
\hline \multirow[t]{4}{*}{$\begin{array}{l}\text { Ventricle } \\
\text { wall size }\end{array}$} & $\begin{array}{l}\text { Right Posterior wall thickness in diastole ( RPWTD ) } \\
(\mathrm{cm})\end{array}$ & $-0.371 *$ & $-0.413 *$ & $-0.417 *$ \\
\hline & Left Posterior wall thickness in diastole ( LPWTD ) $(\mathrm{cm})$ & -0.353 & -0.147 & -0.131 \\
\hline & Right Posterior wall thickness in systole ( RPWTS) $(\mathrm{cm})$ & -0.151 & -0.139 & -0.207 \\
\hline & Left Posterior wall thickness in systole ( LPWTS ) $(\mathrm{cm})$ & -0.125 & 0.032 & -0.085 \\
\hline \multirow{3}{*}{$\begin{array}{l}\text { Inter ventricular } \\
\text { septum thickness } \\
\text { and Left Ventricle } \\
\text { Mass }\end{array}$} & $\begin{array}{l}\text { Inter ventricular septum thickness in diastole (IVSTD) } \\
(\mathrm{cm})\end{array}$ & -0.277 & -0.093 & 0.040 \\
\hline & $\begin{array}{l}\text { Inter ventricular septum thickness in systole (IVSTS) } \\
(\mathrm{cm})\end{array}$ & -0.072 & 0.091 & 0.072 \\
\hline & Left Ventricular Mass ( LV Mass ) (gram) & -0.095 & 0.077 & 0.071 \\
\hline
\end{tabular}

Significant at $0.05=0.361$

Significant at $0.01=0.462$

Table (4) results reveal that there are negative correlations between ventricles morphological variables and freestyle swimming time, i.e. as morphological variables increases as swimming time decreased

Table (5)

Multiple linear regression analysis using step-wise method for effect heart left and right ventricles on $50 \mathrm{~m}$ freestyle time $(\mathrm{n}=30)$

\begin{tabular}{c|l|l|l|l|l|l|l|l}
\hline \hline Multi-linear regression model & $\begin{array}{l}\text { Unstandardized } \\
\text { coefficient } \\
\text { (B) }\end{array}$ & $\begin{array}{l}\text { Standard } \\
\text { Error }\end{array}$ & $\begin{array}{l}\text { Standardized } \\
\text { coefficient } \\
\text { Variables }\end{array}$ & T & $\begin{array}{l}\text { Significance } \\
\text { level }\end{array}$ & $\begin{array}{l}\text { Contribution } \\
\text { ratio }\end{array}$ & $\begin{array}{l}\text { Overall } \\
\text { Contribution } \\
\text { ratio }\end{array}$ \\
\hline \hline A & (Constant) & 35.329 & 1.382 & & $25.571 *$ & 0.000 & - & \\
\hline V1 & $\begin{array}{l}\text { Right ventricle end } \\
\text { Systolic dimension } \\
\text { (RVESD }(\mathrm{cm})\end{array}$ & -2.375 & 0.915 & -0.441 & $-2.597 *$ & 0.015 & $19.4 \%$ & $19.4 \%$ \\
\hline \hline
\end{tabular}


Table (5) results reveal that that $\mathrm{T}$ value is significant and that Right ventricle end Systolic dimension (RVESD) contribute with $19.4 \%$ in $50 \mathrm{~m}$ swimming time

Equation prediction of this model:

50 -meter freestyle swimming time $=35.329-0.441 \times($ Right ventricle end Systolic dimension (RVESD )

Table (6)

Multiple linear regression analysis using step-wise method for effect heart left and right ventricles on $100 \mathrm{~m}$ freestyle time $(n=30)$

\begin{tabular}{|c|c|c|c|c|c|c|c|c|}
\hline \multicolumn{2}{|c|}{$\begin{array}{l}\text { Multi-linear regression model } \\
\text { Variables }\end{array}$} & $\begin{array}{l}\text { Unstandardized } \\
\text { coefficient } \\
\text { (B) }\end{array}$ & $\begin{array}{l}\text { Standard } \\
\text { Error }\end{array}$ & $\begin{array}{l}\text { Standardized } \\
\text { coefficient } \\
\text { (Beta) } \\
\end{array}$ & $\overline{\mathrm{T}}$ & $\begin{array}{l}\text { Significance } \\
\text { level }\end{array}$ & $\begin{array}{l}\text { Contribution } \\
\text { ratio }\end{array}$ & $\begin{array}{l}\text { Overall } \\
\text { Contribution } \\
\text { ratio } \\
\end{array}$ \\
\hline $\mathrm{A}$ & (Constant) & 65.183 & 4.518 & & $14.427 *$ & 0.000 & - & \\
\hline V1 & $\begin{array}{l}\text { Right ventricle end Systolic } \\
\text { dimension (RVESD ) }(\mathrm{cm})\end{array}$ & -4.724 & 1.408 & -0.530 & $-3.355^{*}$ & 0.002 & $19.4 \%$ & $19.4 \%$ \\
\hline & $\begin{array}{l}\text { Left ventricle end Systolic } \\
\text { dimension (LVESD })(\mathrm{cm})\end{array}$ & 4.304 & 1.616 & 0.421 & $2.664^{*}$ & 0.013 & $16.5 \%$ & $35.9 \%$ \\
\hline
\end{tabular}

Table (6) results reveal that that $\mathrm{T}$ value is significant and that Right and left ventricle end Systolic dimension (RVESD) contribute with $35.9 \%$ (19.4\% and $16.5 \%$ respectively) in $100 \mathrm{~m}$ swimming time

Equation prediction of this model:

100 -meter freestyle swimming time $=65.183-0.531 \times$ Right ventricle end Systolic dimension (RVESD )+ 0.421x Left ventricle end Systolic dimension (LVESD )

Table (7)

Multiple linear regression analysis using step-wise method for effect heart left and right ventricles on $200 \mathrm{~m}$ freestyle time $(n=30)$

\begin{tabular}{c|l|l|l|l|l|l|l|l}
\hline \hline Multi-linear regression model & $\begin{array}{l}\text { Unstandardized } \\
\text { coefficient } \\
\text { (B) }\end{array}$ & $\begin{array}{l}\text { Standard } \\
\text { Error }\end{array}$ & $\begin{array}{l}\text { Standardized } \\
\text { coefficient } \\
\text { (Beta) }\end{array}$ & T & $\begin{array}{l}\text { Significance } \\
\text { level }\end{array}$ & $\begin{array}{l}\text { Contribution } \\
\text { ratio }\end{array}$ & $\begin{array}{l}\text { Overall } \\
\text { Contribution } \\
\text { ratio }\end{array}$ \\
\hline \hline $\mathrm{A}$ & (Constant) & 163.469 & 4.543 & & $35.986^{*}$ & 0.000 & - \\
\hline $\mathrm{V} 1$ & $\begin{array}{l}\text { Right ventricle end Systolic } \\
\text { dimension (RVESD) (cm) }\end{array}$ & -5.332 & 2.254 & -0.379 & $-2.366 *$ & 0.025 & $18.1 \%$ \\
\hline & $\begin{array}{l}\text { Right Posterior wall } \\
\text { thickness in diastole ( } \\
\text { RPWTD ) }\end{array}$ & -13.207 & 5.722 & -0.370 & $-2.308 *$ & 0.029 & $13.5 \%$ \\
\hline \hline
\end{tabular}

Table (7) results reveal that that $\mathrm{T}$ value is significant and that Right ventricle end Systolic dimension (RVESD) and Right Posterior wall thickness in diastole (RPWTD) contribute with $31.6 \%$ (18.1\% and $13.5 \%$ respectively) in $200 \mathrm{~m}$ swimming time

Equation prediction of this model:

200-meter freestyle swimming time $=163.469-0.379 \times$ Right ventricle end Systolic dimension (RVESD ) -0.370 x Right Posterior wall thickness in diastole (RPWTD)

\section{Discussion}

Table (5) results show that Right ventricle end Systolic dimension (RVESD) contribute with $19.4 \%$ in $50 \mathrm{~m}$ swimming time. And the prediction equation was 50 -meter freestyle swimming time $=35.329-0.441 \times$ (Right ventricle end Systolic dimension (RVESD). Researchers return this to the increase in left ventricle size which occurs due to training type and energy production system, where $50 \mathrm{~m}$ swimming is the fastest race in swimming. Swimming training in horizontal position increase vein blood return to heart because of systolic and diastolic movements for upper and lower body muscles contributing 
in breathing which make heart adopts to effort. This is consistent with El-Sayed $(2003,254)$ study results which confirmed that sports training processes lead to increase in heart and muscles fibers expansion and strength at the same time; hence an increase in heart size occur, as well as expansion in ventricles fiber in particular.

This results is also consistent with $\mathrm{J}$ scharhag et al $(2010,58)$ which revealed that heart mass increase is due to increase of ventricles wall thickness after muscle strength training. In this regard Abu Zaid (2013) argues that swimming training lead to increase in left ventricles mass within swimmer children.

This result is also in line with what mentioned by $\operatorname{Krol}(2011,23)$ that the increase of vein blood returned to heart lead to stretch in right ventricle fibers, which in turn increase systolic strength and pump more blood through the heart, and the increase in right ventricle dimension is part of the general heart inflation because of continuous increase in right atrium during swimming

This is also consistent with Salem (1997) study, which measured 50 meter swimming for the four swimming types and stroke rate and intensity and some heart physiological and morphological variables to identify technical and record performance. The results indicated that one time training daily lead to same result as two times training daily in technical performance, record, and heart physiological and morphological variables

Table (6) results reveal that Right and left ventricle end Systolic dimension (RVESD) contribute with $35.9 \%$ (19.4\% and $16.5 \%$ respectively) in $100 \mathrm{~m}$ swimming time and the prediction equation was 100 -meter freestyle swimming time $=65.183-0.531 \times$ Right ventricle end Systolic dimension (RVESD )+ 0.421x Left ventricle end Systolic dimension (LVESD ). Researchers return this to that right and lift ventricles in systolic significantly affect $100 \mathrm{~m}$ freestyle swimming time because of what mentioned above that the increase in ventricles size occur depending on training type and energy system. This result is also in line with what mentioned by $\operatorname{Krol}(2011,23)$ that the increase of vein blood returned to heart lead to stretch in right ventricle fibers, which in turn increase systolic strength and pump more blood through the heart, and the increase in right ventricle dimension is part of the general heart inflation because of continuous increase in right atrium during swimming

Researchers attribute this also to ventricles adoption where Inter ventricular septum thickness give force to systolic of left and right ventricles. This is consistent with D'andrea eta al $(2013,48)$ who confirmed that right ventricle wall is positively influenced in heart diastolic function by increase pre-load for athletes

This is also consistent with Dewidar (2014) study results which revealed the effect of swimming training and standardized training program on formation of athletic heart within junior swimmers 11-12 years (study sample), as heart function improved I terms of left and right ventricles size, thickness, and dimensions. The matter which indicate significance effect if swimming training in developing heart function and formation of athletic heart.

This results also agreed with Younis (2007) study results which revealed that swimmers were characterized by increase in the following heart morphological variables (relative) : Aorta valve hall, left atrium dimension, right and left ventricles dimension in diastolic, left ventricle size in systolic and diastolic. And that most biological variables (functional and morphological) increase with age and training age.

Table (7) results reveal that Right ventricle end Systolic dimension (RVESD) and Right Posterior wall thickness in diastole (RPWTD) contribute with $31.6 \%$ (18.1\% and $13.5 \%$ respectively) in $2000 \mathrm{~m}$ swimming time and the prediction equation was : 200-meter freestyle swimming time $=163.469-0.379 \times$ Right ventricle end Systolic dimension $($ RVESD $)-0.370$ 
$\mathrm{x}$ Right Posterior wall thickness in diastole (RPWTD). Researchers return this also $t$ aerobic and anaerobic o training loads in swimming which is performed in horizontal position, which in turn leads to increased amount of vein blood return to heart as a result of muscles systolic and diastolic movements; which lead to increased amount of blood pumped through the aorta artery in order to provide the body with what it needs from oxygen and transfer energy waste from working muscles, continuing this performance increase aorta diameter to be able to absorb greater amount of blood with each contraction, which has a positive effect on the thickness of ventricle rear wall. This is agreed with what indicated by Fuster et al $(2001,22)$ that training continuity, volume and intensity are of the important variables affecting heart morphology

This is also consistent with El-Sayed (2003, 182), and Salama (2000, 85) who mentioned that systolic power occur as a result of morphological increase in heart muscle fibers thickness of, especially ventricles 85)

Adnan, et al (2010), results reveal that physiological variables contribution differ between $50 \mathrm{~m}, 100 \mathrm{~m}$ and $200 \mathrm{~m}$ researchers recommended use physiological variable as per contribution percentage while setting training program for swimmers and depend on physiological variables in evaluation training programs)

Omar study (2001) concluded that contribution order of biological variables order is different for boys than girls in 100 meters and 200 meters swimming, and arrived to prediction equation using swimming biological variables except rest.

From what mentioned above, the following is concluded: Right ventricle end Systolic dimension (RVESD ) contribution was $19.4 \%$ in $50 \mathrm{~m}$ and $100 \mathrm{~m}$ and decreased to $18.1 \%$ in 200m, in 100m Right and left ventricle end Systolic dimension (RVESD) contribute with $35.9 \%$ (19.4\% and $16.5 \%$ respectively) in $100 \mathrm{~m}$ swimming time. In 200m Right ventricle end Systolic dimension (RVESD) and Right Posterior wall thickness in diastole (RPWTD) contribute with $31.6 \%$ (18.1\% and $13.5 \%$ respectively) and it was arrived to prediction equations of freestyle swimming time using morphological variables

\section{Conclusions:}

In light of research objectives and sample limits the following could be concluded:

1 - Overall contribution percentage in $50 \mathrm{~m}$ is $19.4 \%$ with one variable only namely: Right ventricle end Systolic dimension (RVESD )

2- Overall contribution percentage in $100 \mathrm{~m}$ is $35.9 \%$ with two variable namely: Right and left ventricle end Systolic dimension (RVESD ) with contribution percentage (19.4\% and $16.5 \%$ respectively)

3- Overall contribution percentage in $200 \mathrm{~m}$ is $31.6 . \%$ with two variable namely: Right ventricle end Systolic dimension (RVESD ) and Right Posterior wall thickness in diastole (RPWTD) with contribution percentage (18.1\% and $13.5 \%$ respectively)

4- it was arrived to prediction equations of freestyle swimming time using morphological variables

\section{Recommendations:}

Within study sample limits and in the light of results and statistical processes, researchers recommend the following:

1- Use left and right ventricles morphological variable as per contribution percentage while setting training program for junior swimmers

2- Depend on left and right ventricles morphological variable and prediction equation concluded in this research as an evaluation and direction mean of training process to achieve the desired performance from athletes and make new records. 
3- It is necessary to periodically measure heart morphological and functions variables for swimmers to be used as an indicator to judge physiological adaptation to training loads, and development of training programs in proportion to the results of these periodic measurements.

4- Depend on heart physiological and functional variables which have significant effect in this study as one of swimmers selection bases, especially Right and left ventricle end Systolic dimension (RVESD ), and Right Posterior wall thickness in diastole (RPWTD)

5- Get benefit of these results in medical field to differentiate between physiological changes resulted from training adaption and those resulted from respiratory system diseases

6- Further studies to be conducted to identify morphological and functional variables that occur to heart in different swimming races and in the four swimming methods

7- It is necessary to use Echocardiograph device to evaluate heart efficiency before start swimming to ensure heart safety and that heart is free of diseases, especially before setting any training program to ensure heart efficiency in adopting with high training loads.

\section{References}

1- Abdel Fattah, Abu Ela Ahmed (1997). Sport morphology and physiology and evaluation measurement methods. . Cairo Arab Thought House, (p.23 - 25, 56). (in Arabic language)

2- Abdul Hadi, Ayed (2001). Human body physiology, Jordan: Sunrise House for publication and distribution . (in Arabic language)

3- Abu Zaid, Magdy Mohammed (2013). Athletic hart for children swimmers in prepuberty. Fifth International Scientific Conference, sports culture between reality and ambition. Yarmouk University. 3-4 April. (in Arabic Language)

4- Abu Zaid, Magdy Mohammed (2013). Quality Management in scientific research field in Universities. The First International Scientific Conference. Outlook vision for education future in Egypt and Arab world in light of contemporary societal changes. Mansoura University. (in Arabic Language)

5- Abu Zaid, Magdy Mohammed (2013). Sports and Orthopedic Health . Prince Faisal bin Fahd Award, sixth session. sports medicine aspect - first rank in half. Saudi Arabia. . (in Arabic Language)

6- Adnan, Asaad; Elsafy, Aziz, Gawad , Gamil kazem (2010). Record contribution percentage in terms of some physiological variables within $50 \mathrm{~m} 0.100$ and 0.200 meter freestyle swimmers, Maysan Journal of Science, University of Misan, Iraq.

7- Al-Bek, Ali Fahmi (2009). Modern trends in sports training, theories and application, vol. III. Training methods to develop anaerobic and aerobic abilities. Alexandria: knowledge establishment (p. 25-35) . (in Arabic Language)

8- Ali, Yusuf Dahab (1994) General and sport physiology, Cairo: Huriya Library. (in Arabic language)

9- Ali, Yusuf Dahab (2000). General and sport physiology, Cairo: Huriya Library. (in Arabic language)

10- Ayabakan C, and Akalin F.(2006) Athletes heart in pre pubertal male swimmers . Cardiol Young. Feb 16 (1), 61-6 
11-Dahab, Yusuf Ali, Ali, Sana Abdul Salam, and Abdel Nasser, Gamal(2008). Heart morphological and functional changes and some blood hormones changes withib swimmers in different ages - fourth regional conference - Faculty of Physical Education Abu Qir - Part V. (in Arabic language)'

12- D'Andrea a, Riegler L, Golia R, et al.(2013). Range of right heart measurements in top-level athletes: The training impact. Int J Cariol. 20;164(1):48-57.

13-Darwish, Ganat and Abdul Salam, Sanaa (2007). Sports physiology. $6^{\text {th }}$ ed., Alexandria : Technical radiance library and Press. (in Arabic language)

14- Dewidar, Mustafa Mahmoud(2014). Effect of an intensive training program on right ventricle function for junior swimmers, unpublished $\mathrm{PhD}$ Thesis, Faculty of Physical Education for Men, Alexandria university. 9in Arabic language)

15- El-Sayed, Ahamd Nasrulddin (2003). Sports Physiology (theories - applications). Cairo: Arab Thought House( 254-255) (in Arabic language)

16- Fuster v, Alexander, R.W. O'rourke R.A, Roberts, R., King, S.B.\& Wellens , H.J.J,.(2001). Hurst's the heart, $10^{\text {th }}$ ed., volume 2. Toronto : Mc Graw-Hill.

17-Hilmi, Isam Mohammed Amin(1998). Youth training strategy in swimming. Alexandria: Knowledge establishment (P. 17-33, 395 - 397) . (in Arabic Language)

18- Koc M, (2007) Right and left ventricules adaptation to training determined by conventional echocardiography and tissue Doppler imaging in young endurance athletes .Acta Cardiol.;62(1):13-8 feb

19- Krol W, and Braksator W. (2011). The influence of extreme mixed exertion load on the right ventricular dimensions and function in elite athletes: a tissue Doppler study. Echocardiography. 28(7):753-60 Aug 2011

20- Omar, Omar Shukri (2001). relative contribution of some biological indications in short swimming (100m / 200m) record, scientific journal of Physical Education Girls. Alexandria (20).

21- Pelliccia, A; et al (2014). Morphological and functional adaptation of left and right atria induced by training in highly trained female athletes. Circ Cardiovasc Imaging. ;7(2):222-9

22- Powers, S. K., Howely, E. T. (1994). Exercise physiology theory and Application to fitness، second edition، U.S.A . (pp 171-195, 202-215)

23-Salama, Bahauddin (2000). Sports physiology and physical performance (blood lactate), Cairo :Arab Thought house.

24-Salem, Hazem Hussein (1997) effect of training load quality and quantity on some heart physiological and morphological characteristics and performance level among junior swimmers under 10 years ", Master Thesis, Faculty of Physical Education for Men, Helwan University. (in Arabic language)

25-Scharhag, J, Thunenkotter, T et al . Echocardiography of the right ventricle in athlete's Heart and hearts of normal size compared to magnetic resonance imaging. Int J Sports Med. 2010 Jan;31(1):58-64

26- Weyman, A E. (1994). Principles and Practice of Echocardiography. Williams \& Wilkins. 
27- Younis, Gamal Abdel Nasser (2007). Dynamics of some heart biological characteristics within junior swimmers, unpublished $\mathrm{PhD}$ thesis, Faculty of Physical Education for Men. Alexandria University. (in Arabic language).

28-Zaher, Abdul Rahman Abdul Hamid (2005). Descriptive and functional Anatomy principles. Cairo: book publishing center. (in Arabic language)

29- Zaher, Abdul Rahman Abdul Hamid (2011). Sports physiology encyclopedia. Cairo: book publishing center. (in Arabic language) 